\title{
PORTARSE MAL, DECIR ALGUNA VERDAD: LA FUNCIÓN DE LA CONFESIÓN EN LA RAZÓN EVALUADORA
}

\section{MISBEHAVING, TELLING SOME TRUTH: THE ROLE OF CONFESSION IN THE EVALUATIVE REASON}

\author{
Facundo Giuliano \\ giulianofacundo@gmail.com

\begin{abstract}
Consejo Nacional de Investigaciones Científicas y Técnicas. Universidad de Buenos Aires (Argentina)
\end{abstract}

Recibido: $18 / 02 / 2020$

Aceptado: $20 / 07 / 2020$

\begin{abstract}
Resumen:
El presente ensayo explora el lugar de la confesión en el marco de la razón evaluadora, indagando sus vínculos y continuidades e intentando detectar la funcionalidad de una en la otra. Para ello, se toma como excusa un discurso evaluador reciente y, al mismo tiempo que se lo discute, se explora la manera en que la confesión pervive en retóricas evaluadoras que colonizan la educación contemporánea. De este modo, podrá observarse cómo estudiantes y docentes pueden convertirse en sujetos confesantes en el marco de un tipo racionalidad que seduce con su ofrecimiento de otorgar inteligibilidad, pero termina por clasificar singularidades en función de concepciones pre-establecidas. Por último, se plantean una serie de preguntas (junto a una evocación) que giran en torno a las potencialidades de resistencia frente a estas prácticas de poder.
\end{abstract}

Palabras claves: Filosofía de la Educación, Ética, Razón evaluadora, Pedagogía, Confesión, Examen.

\begin{abstract}
This essay explores the place of confession within the framework of the evaluative reason, investigating its continuities and trying to detect the functionality of one in the other. For this, a recent evaluative discourse is taken as an excuse and, at the same time as it is discussed, the way in which confession survives in evaluating rhetoric's that colonize contemporary education is explored. In this way, it will be possible to observe how students and teachers can become confessing subjects within the framework of the rationality type that seduces with its offer to grant intelligibility, but ends up being classified singularities according to pre-established conceptions. Finally, a series of questions are posed (together with an evocation) that revolve around the potentialities of resistance to these power practices.
\end{abstract}

Keywords: Philosophy of education, Ethics, Evaluative reason, Pedagogy, Confession, Exam. 


\section{Introducción entre dimes y diretes: de la solicitud de confesión al desciframiento ontológico.}

En un escrito de 1930 a propósito del amor y el trabajo, Deodoro Roca (2008) plantea que "Por la manera particular de resolver -o de intentarlo, o también de fracasar en el intento- esas dos cuestiones definen cada biografía humana, cada fisonomía nacional, cada caracterización cultural de un período de la historia" y luego evoca la frase "Dime cómo has querido, dime cómo te has ganado la vida -parafrasea D'Ors- y te diré quién eres" (p. 100). El refrán de base, que ya pertenece a la cultura popular y llega a encontrarse hasta en el Quijote de Cervantes, posee un doble movimiento: solicitar una revelación (que bien podría ser una confesión) y ofrecer a cambio otra que (no precisamente confesional) promete un desciframiento ontológico. Como puede observarse, los motivos de la solicitud varían según la ocasión y el interés en juego: en lo que podría llamarse la "versión original" del refrán se referencia a la compañía para determinar, por alguna de sus características, una respuesta al quién se es... No obstante, vemos que también puede involucrar formas de hacer que rondan lo íntimo: cómo se ama o cómo se ha ganado alguien la vida.

En tal sentido, y siguiendo la pista deodoriana, pretendemos explorar la relación entre un tipo de trabajo que impostada y artificiosamente suele relacionárselo al sentimiento amoroso (aunque poco tenga de él o su evocación sea una mera pose) para otorgarle una dimensión más "humana" o compasiva, pero que al fin y al cabo entraña algún tipo de vínculo con el dispositivo de la confesión que forma parte de la razón evaluadora. Es así que encontramos fórmulas como "Evaluar con el corazón", de la cual derivan fraseos tales como "Dime cómo evalúas y te diré qué tipo de profesional y de persona eres" (Santos Guerra, 2017, p. 10). En esta instancia, la promesa de desciframiento ontológico se desliza del clásico 'quién' a una promesa que devolvería una doble clasificación: en tanto tipo de profesional y en tanto tipo de persona. Esto último invita a profundizar un poco más el análisis de los vínculos entre la razón evaluadora y el dispositivo de la persona (Giuliano, 2019), pues, atendiendo lo señalado por Esposito (2011) no puede soslayarse la paradoja de que

cuanto más se trata de recortar las características inconfundibles de la persona, tanto más se determina un efecto, opuesto y especular, de despersonalización. Cuanto más se quiere imprimir el marco personal de la subjetividad, tanto más parece producirse un resultado contrario de sometimiento a un dispositivo reificante (p. 11).

Se trata de un dispositivo orientado hacia "la división del género humano en categorías claramente diferenciadas y rígidamente subordinadas unas a otras" y hacia "la posibilidad de reducir a otros a la condición de cosa" (Esposito, 2011, pp. 19-23), ubicado en la sustancial indistinción entre sujeto y objeto, entre subjetivación y sometimiento, lo que le permite subjetiva a través del sometimiento o la objetivación. Por ende, cuando vemos los procesos de reificación y cosificación que involucra en forma primordial a la razón evaluadora, bien podría verse en ella ese "resto escondido" que constituyó a la "civilización cristiano-burguesa" y que continúa operando en plena luz y suelo de nuestro tiempo. Después de todo, es el prisma móvil desde cuya perspectiva se separa o divide jerárquicamente las diferencias en función de objetivos siempre cambiantes. Desde ese fondo móvil, se recorta el perfil de la cosa evaluada puesto que aquello que no se considera "personal" puede ser evaluado (es decir, reificado, cosificado o, básicamente, devaluado) con suma tranquilidad y este es su funcionamiento deshumanizador. Por eso "máscara" es otro significado para "persona" y, una vez salvaguardado su dispositivo, no importa lo que ocurra en el rostro sobre el que se apoya y, menos aún, en los rostros que no la poseen. 
Así entonces, retomando el planteo que nos llevó al anterior excurso, al evaluar lo que se pone sobre el tapete confesional serían concepciones (sobre estudiantes, sobre la sociedad, la escuela, la docencia, la enseñanza, el aprendizaje, la inteligencia), principios (sobre la estructura y la dinámica social, sobre la finalidad de las instituciones, sobre las exigencias morales de la profesión) y actitudes (hacia sí mismo, hacia evaluados, hacia colegas). De esta manera, quisiera insistirse en que la evaluación no sería un fenómeno meramente técnico sin que influyan en ella sentimientos y emociones, o elementos de carácter "ético", con consecuencias en la autoestima y el auto-concepto. Su apuesta radica en mejorar la racionalidad evaluadora y para ello plantea diversas dicotomías que definirían moralmente concepciones, principios y actitudes. A pesar de que se hace hincapié en una dimensión pretendidamente "ética", notamos que se trata de un planteo moral no solo por sus apuntados efectos moralizantes, sino también por cimentarse sobre regularidades ficcionales, normalizaciones y polos que prescriben de antemano su positividad o su negatividad según lo devele la evaluación en cuestión.

Por ejemplo, en relación a las concepciones sobre la sociedad, se dice que, si se la entiende con sus desigualdades naturalizadas, la evaluación sería un sistema de selección y discriminación; por el contrario, si se la entiende desde la solidaridad y la igualdad, sería un sistema "nivelador" y no alimentador de las desigualdades tratando de ayudar a "quienes no tienen medios" (Santos Guerra, 2017, p. 40) -énfasis nuestro-. Del mismo modo, las concepciones sobre la escuela harían de la evaluación un proceso para comprobar o una reflexión "concienzuda" sobre procesos de desarrollo intelectual y humano; las concepciones sobre estudiantes harían de ella un proceso de mediciones o un proceso de reflexión "compartida"; las concepciones sobre el aprendizaje harían de ella un modo de saber si se ha memorizado lo esperado o un proceso de "diagnóstico, estimulación y comunicación"; las concepciones sobre la docencia harían de ella una constatación de la asimilación adecuada o un modo de mejora; las concepciones sobre la inteligencia podrían dotarla de mayor facilidad para clasificar o de mayor apertura a la flexibilidad. De este modo, la evaluación "develaría” las concepciones de quien evalúa.

El planteo gravita sobre el telón de fondo que se sostiene en ideas como las desigualdades de puntos de partida, la inferioridad de condiciones y la certeza de que los (buenos) resultados se utilizan para seguir en el sistema, elegir con mayor libertad, acceder a mejores opciones laborales, alimentar las expectativas y la motivación a partir de ello. Curioso fondo para un planteo que dice no estar a favor de la "política del etiquetado", que condiciona expectativas y predispone al fracaso, pero ya etiqueta de entrada a "desiguales" e "inferiores" definidos por su falta o lo que "no tienen". Sorprende también que los pares que representan la forma que tomaría eventualmente la evaluación, según la concepción sobre el asunto señalado, sean formulados como dicotómicos entre ellos y negando su mutua imbricación. Como si la evaluación "niveladora" y "solidaria" no pudiera ser también un sistema de selección y discriminación, o como si la evaluación en forma de reflexión "concienzuda" y "compartida" estuviera exenta de procesos de comprobación y medición. Como si la razón evaluadora por el mero hecho de montarse positivamente sobre el diagnóstico, la estimulación, la comunicación, la mejora y la flexibilidad, se desentendiera de sus formas de constatación, ya sea de la asimilación adecuada o la memorización esperada, y de su manía para clasificar.

Pero también la evaluación permite "desvelar" las actitudes de quien evalúa, principalmente en tres registros: I) hacia sí mismo, la evaluación puede mantener una posición de humildad -si se tiene la conciencia de que parte del aprendizaje depende de la forma en que se ha enseñado- o una posición sádica -si se vive desde la displicencia-; II) hacia quienes se evalúa, puede emplearse como estímulo o como instrumento de opresión -como arma que amenaza y castiga; III) hacia colegas, puede ser una práctica individualista/egocéntrica o grupal. Nuevamente, como suele suceder en este tipo de dicotomías que funcionan más como binarismos consensuales que como antagonismos políticos, se pierde de vista la convivencia de ambas caras 
en la misma cabeza que aloja la racionalidad evaluadora. Cualquiera podría evocar las imposturas vividas en el marco de este tipo de racionalidad: posiciones humildes que encubren un gran sadismo evaluador, estímulos evaluadores que buscan el consentimiento para disimular la opresión y que la consecuencia (o el castigo) recaiga lo más felizmente posible en quien se evalúa, la impostación de la grupalidad y la cooperación para dar un marco progre a los egocentrismos de turno.

Sobre los principios que la evaluación "desvela", y aquí esta palabra ya nos suena más en su primer significado (quitar el sueño a alguien) que en el segundo atribuido (descubrir lo que estaba oculto), también encontramos que giran en torno a tres niveles de concepciones: I) sobre la estructura y la dinámica social, la evaluación tendría que ver con una racionalidad de justicia (sensible a las desigualdades de base) o con una racionalidad tecnicista aséptica "poco sensible a las diferencias" (Santos Guerra, 2017, p. 52); II) sobre la finalidad de las instituciones, según lo que se piense de ellas, la evaluación puede ser tendente a establecer rigurosas competencias clasificadoras o más individualizada y sensible a las diferencias; III) sobre las exigencias morales de la profesión, la evaluación podría enfocarse en la dimensión técnica del aprendizaje, el progreso y el éxito académico o en los principios básicos de "la relación humana" y el ejercicio de la responsabilidad. Pero las didácticas mismas de la evaluación se dedican a promover criterios técnicos de "justicia" para dotar de mayor legitimidad y convencimiento a su proceder evaluador, así como también a establecer evaluaciones "personalizadas" o "sensibles a las diferencias" que no abandonan las competencias ni las clasificaciones, al igual que en el nombre de la responsabilidad profesional y de principios "humanistas" justifican una noción de aprendizaje despojada de enigma y siempre verificable, constatable, medible y fácilmente inscribible en una escala de éxito.

Ahora bien, el círculo "virtuoso" no se cierra si no se propone más evaluación para mejorar la evaluación. Es así que el autor de "Evaluar con el corazón" sostiene que es preciso poner "en tela de juicio" las prácticas evaluadoras, lo que supondría poner en entredicho el entramado de principios, exigencias y normas, para comprenderlas y mejorarlas o generar nuevas. Esto también incluye evaluar la docencia, ya que así "será más fácil mejorar los procesos de aprendizaje", entendiendo por mejora "no solo la multiplicación de sus exigencias técnicas sino la racionalidad de la práctica y el respeto a la equidad" (Santos Guerra, 2017, pp. 53-54). Sobre esta última palabra, no podemos olvidar la fuerza que adquirió de mano de organismos internacionales como el Banco Mundial y las reformas educativas neoliberales que también enarbolaron la bandera de la equidad (siempre en detrimento de la igualdad). Por lo demás, el repertorio fue casi anticipado cuando hablábamos anteriormente de los criterios técnicos de justicia y de la inclinación a mejorar este tipo de racionalidad. Dicha inclinación, u obsesión, por la mejora nos recuerda al Nietzsche (2013) del Crepúsculo de los ídolos cuando allí ironizaba sobre los "mejoradores" de la humanidad que ven en la doma (una disciplina que involucra pruebas y un jurado que otorga puntos) un mejoramiento, pero que no es más que un debilitamiento "mediante el afecto depresivo del miedo, mediante el dolor, mediante las heridas, mediante el hambre" (p. 94).

Luego del recorrido por un texto que maquilla de sentimiento amoroso un trabajo de verdugo tecnificado, notamos que la promesa de doble clasificación ontológica finalmente queda incumplida. A lo mejor la intención sea que se infiera el tipo de persona y de profesional que se es en función de los desvelamientos que el tipo de evaluación en cuestión realizaría en materia de concepciones, actitudes y principios. En ese "descubrir lo que estaba oculto" y que se confiesa en la manera de concebir y practicar la evaluación, tal vez deba hallarse la clasificación correspondiente a cada quien. No explicitaremos aquí lo que se trasluce del simple ejercicio de ubicar en una misma línea el tipo de profesional y de persona que se es con el tipo de evaluación que se pregona (según concepciones, actitudes y principios), dejamos el morbo clasificador a 
quien quiera jugar un rato con ello. Lo que sí nos interesa subrayar es el carácter circular de este asunto en el que al mismo tiempo que se señala a alguien como un tipo de profesional y de persona que piensa las instituciones como filtros sociales $y$, por tanto, tiende a evaluar estableciendo "rigurosas competiciones clasificadoras", ese mismo alguien ya está siendo clasificado.

De ahí que el "dime cómo evalúas y te diré qué tipo de profesional y de persona eres", además de pedir un desvelamiento o confesión, lo que en realidad ofrece a cambio en la transacción, más que de un desciframiento ontológico se trata de una clasificación social. Por ello resulta relevante indagar con mayor profundidad la función de la confesión en la razón evaluadora. Para esto nos meteremos a escuchar y analizar algunas de las clases que Michel Foucault ofreció sobre esta cuestión, en Bélgica, a comienzos de la década de 1980.

\section{La confesión en la razón evaluadora}

En la conferencia inaugural de su curso, Foucault (2014) plantea que detrás de la confesión se presiente el vínculo entre la pureza y el decir veraz, una función purificante por la que "decir la verdad" se caracterizaría y permitiría arrancar el mal del cuerpo y del alma o expulsarlo al confesar. En cierta forma, anular, borrar o conjurar esa verdad misma que, al ser revelada, se inmiscuye en tejidos rituales densos y complejos. Pero declarar solemne o ritualmente que se ha hecho algo no basta para constituir una confesión ya que

la confesión es más que una mera declaración, pero es otra cosa que la declaración de una falta cometida por el sujeto hablante. (...) Lo que separa una confesión de una declaración no es lo que separa lo desconocido de lo conocido, lo visible de lo invisible, sino lo que podríamos llamar cierto costo de enunciación. La confesión consiste en pasar del no decir al decir suponiendo que el no decir tiene un sentido preciso, un motivo particular, un valor importante. (...) O aún más: cuando alguien declara su amor, se tratará de una confesión si el hecho de declararlo implica el riesgo de tener un costo. (...) Conocida pretensión del poder que quiere forzar a ser libres a aquellos a quienes somete. Y sin embargo, en sentido estricto la única confesión que puede haber es la confesión libre. Bien lo sabían los inquisidores de la Edad Media: para que las declaraciones arrancadas bajo la tortura fueran confesiones, era menester que se repitieran tras el suplicio. (Foucault, 2014, p. 25) -énfasis nuestro-.

Pero, ¿qué garantía de libertad hay en la confesión si se llega a ella mediante algún ejercicio de poder que, incluso luego del mismo, requiere una repetición? Reservamos unas comillas entonces para la "libertad" de esa "única" confesión que no se desprende del poder que somete a quienes en apariencia mayor "libertad" da. Como en una evaluación diagnóstica que brinda "libertad" para inventar un relato a partir de elementos pre-codificados y que, luego de cruzar sus variables con otros test, dirá si alguien puede ser admitido en una institución o en un empleo. Hasta el inconsciente se confiesa, si se expone a los dispositivos adecuados. Y siempre hay un costo de enunciación, un elemento que ya estaba presente en los exámenes de conciencia y que se presentifica de modos diversos en la razón evaluadora. Puede ser el caso de esas evaluaciones en las que algunos de sus ítems pueden dejarse sin contestar, pero que, si se lo hace, y se lo hace bien, suma doble, y si se lo hace mal, resta triple. O como veíamos anteriormente en el "dime cómo evalúas...", ciertamente no se declararía una falta, pero se expondría algo que posee el costo de ser tal o cual tipo de profesional y de persona. Aquí corresponde agregar que

la confesión no es simplemente una comprobación acerca de uno mismo. Es una especie de compromiso, pero un compromiso muy particular: no obliga a hacer tal o cual cosa; implica que quien habla se compromete a ser lo que afirma ser, y precisamente porque 
lo es. (...) En la confesión, quién habla se obliga a ser lo que dice ser, se obliga a ser quien ha hecho tal o cual cosa, quien experimenta tal o cual sentimiento; y se obliga porque es verdad. (...) En sentido estricto, sólo hay confesión dentro de una relación de poder a la que aquella brinda la oportunidad de ejercerse sobre quien confiesa. (...) En una palabra, la confesión suscita o refuerza una relación de poder que se ejerce sobre quien confiesa. Por eso no hay confesión que no sea "costosa" (Foucault, 2014, p. 26).

En la razón evaluadora el costo del paso a lo dicho, de la asunción de lo dicho en el cuerpo que lo sostiene, tiene forma de calificación. No solo de cifra o letra, sino de calificación ontológica: a partir de lo confeso en la evaluación (o el examen que es su instrumento) se adquiere un nuevo status ontológico, una nueva marca de ser o no-ser, un compromiso con esa construcción que llega a poseer valor de "verdad", que plantea una dependencia del visto de otro y una nueva forma de relación con sí mismo. En palabras de Foucault (2014):

La confesión, a la vez que vincula al sujeto a lo que afirma, lo califica de otro modo respecto de lo que dice (...) la confesión es un acto verbal mediante el cual el sujeto plantea una afirmación sobre lo que él mismo es, se compromete con esa verdad, se pone en una relación de dependencia con respecto a otro y modifica a la vez la relación que tiene consigo mismo. (...) Pero si nos atenemos a "nuestras" sociedades -a las sociedades cristianas occidentales-, me parece que podríamos hablar, sin conjeturar en exceso, de crecimiento masivo de la confesión, no de crecimiento continuo, sino gradual y por áreas, por sacudidas repentinas, con detenciones y aceleraciones bruscas. Ese crecimiento tiende -y este es sin duda uno de los rasgos de nuestras sociedades - a vincular cada vez más al individuo con su verdad ( $y$ me refiero a la obligación de decir la verdad sobre sí mismo), hacer actuar ese decir veraz en sus relaciones con los otros y a estar comprometido con la verdad que ha dicho (p. 27).

Signo de ese crecimiento masivo, gradual y por áreas, de la confesión es su extensión en instituciones como las educativas (y no necesariamente confesionales) donde podríamos pensar que hasta el día de hoy se aloja en ellas, pero por otros medios, tal como podríamos ver en la razón evaluadora. Así como también podría rastrearse su relación e imbricación con el cristianismo, por ejemplo, en relación con la penitencia y el examen de conciencia (dos elementos que luego se fusionarán en el examen secularizado más propio del poder disciplinario y no estará exento de su costado punitivo). Lo que pareciera mantenerse como una continuidad, a pesar de los cambios y reformulaciones de las relaciones de poder, es la relación con el problema de la verdad, la ineludible dependencia con el acto de decir la verdad o lo que Foucault (2014) llama "veridicción", sin la cual no podría haber confesión, y que comporta consecuencias tanto para quien la dice como para quien la recibe. Algo similar sucede en la evaluación, que presupone una relación con la verdad al mismo tiempo que no solo no admite la deshonestidad, sino que también la castiga. En este terreno donde lo semiótico y lo estratégico están perpetuamente ligados, se instala lo que Foucault (2014) llama el "gobierno por la verdad" e involucra "tecnologías del sujeto" mediante las cuales alguien se ve inducido, por sí mismo o la dirección de otro, a "transformarse y modificar su relación consigo mismo" (p. 33).

La relación examen-confesión con el cristianismo puede verse con mayor detalle en el volumen IV de la Historia de la sexualidad, donde Foucault (2019) resalta que es sobre la verdad la pregunta que el examen hace a los pensamientos y su función es la de establecer una diferenciación que permita seguir el camino recto, es decir, trata de someter a prueba la "calidad de los pensamientos", pero ahí es donde se instala una duda sobre el pensamiento que se forma en el examen y lo que funda la necesidad de una confesión que esté lo más cerca posible del mismo, "debería poder ser su aspecto exterior, la faz verbal vuelta hacia el otro. La mirada sobre sí mismo y la verbalización de lo que ella capta deberían ser una sola cosa." (p. 159). De este modo, articular palabras, pronunciarlas, dirigirlas a otro, serían acciones con el poder de disipar 
las ilusiones y conjurar las malas ideas mediante una fuerza propia de la confesión: la de decir, mostrar, expulsar, aunque también se diga "liberar". Allí donde el examen fracasa en la resolución de confusiones, en la disipación de ilusiones o en la diferenciación de la proveniencia de lo manifiesto, se instala la confesión como una necesidad perpetua que lo acompañe y le posibilite ser un mejor juez.

A fin de cuentas, el juego del examen-confesión se basa en que "la mirada de uno sobre sí debe asociarse sin cesar al 'decir veraz' acerca de sí mismo", lo que implica "la práctica de un examen ininterrumpido de sí ligado a una confesión incesante ante a otro" (Foucault, 2019, pp. 163-164) que no es otra cosa que una ligazón permanente al deber y la obediencia. Se plantea entonces como una tarea infinita y sin descanso (permear cada vez más los secretos del alma, discernir los pensamientos) enmarcada en la paradoja esencial que caracteriza a estas prácticas de espiritualidad cristiana: "la veridicción de uno mismo está fundamentalmente ligada a la renuncia de sí. El trabajo sin término para ver y decir la verdad de uno mismo es un ejercicio de mortificación" (Foucault, 2019, p. 165). Ahora bien, Foucault (2019) documenta que este dispositivo complejo "donde el deber de sumergirse indefinidamente en la interioridad del alma se acopla a la obligación de una exteriorización permanente en el discurso dirigido a otro, y donde la búsqueda de la verdad de sí debe constituir cierta manera de morir" (p. 165), posee fuentes que remiten a la Antigüedad y los autores cristianos no ocultaron la influencia de filósofos paganos como Pitágoras, Séneca o Epicteto.

Luego de este breve desvío, interesa volver ahora a la última clase del curso sobre la función de la confesión en la que Foucault (2014) habla de ella como una forma cultural que "sigue siendo una práctica social por fuera de la institución judicial" y supone un sujeto confesante que es siempre incitado a decir lo que se le pregunta, pero "siempre dice menos de lo que se espera y siempre, en parte, otra cosa" (p. 218). Siguiendo el planteo, podría observarse que, desde el Medioevo, se asiste a una suerte de "gran juridización" de la sociedad y la cultura occidental que comienza haciéndose visible en las instituciones y prácticas del cristianismo y posteriormente en las del estado secular. En este marco, la importancia de la confesión reside en su ubicación entre el procedimiento acusatorio y el procedimiento inquisitorio, de la cual queda una combinación entre "la constatación de una prueba y la corroboración de una verdad mediante un sistema de demostración" (Foucault, 2014, p. 221) al que se somete el testimonio del sujeto sobre sí mismo. Consideramos que estas son las coordenadas principales de la confesión que perviven en la evaluación y su tipo de racionalidad que no funciona sin la constatación de una prueba y la corroboración de un sistema de demostración a partir del cual se encorseta el testimonio de un sujeto. Claro que se puede resistir o ceder a la prueba inquisitoria, a esa "práctica reglamentada" o "ejercicio bien determinado" (Foucault, 2014, p. 222) sobre todo en el valor de cada uno de sus elementos que conformarían una "certeza perfecta" sobre lo buscado en el otro y que, en la medida de lo encontrado, el juez/evaluador puede dictar su sentencia. El punto es que si "falla" la prueba hay una obligación de repetirla que ya se asoma como amenaza y siembra un miedo a veces lo suficientemente sugestivo como para oponerle resistencia. Es entonces cuando cobra protagonismo la razón punitiva.

Un tribunal no puede sentenciar un castigo a quien previamente no ha prestado algún tipo de consentimiento a la ley que lo atraviesa, un principio penal que también hace de lo confesable una forma de la auto-punición. Y esto precisamente porque otorga fundamentos validadores $y$ legitimadores al juez/evaluador para que "falle" (sentencie, castigue, condene) en función de una voluntad compartida (por jueces y culpables) que busca reinstaurar el pacto social y marcar así el primer paso de una reintegración. De este modo, "la confesión es un acto que cobra sentido en la raíz misma del sistema punitivo" en un juego funcional de reconocimientos que manifiesta como verdad "lo que es el ejercicio del derecho a castigar" (Foucault, 2014, p. 225). Lo que entra en escena en esta instancia es la conciencia evaluadora (sea del juez o de un jurado) 
que en su propia soberanía y autoridad establece una prueba como irrecusable y evidente donde cálculo y unidades de medida se subsumen en asunto común a todos. Desde luego, a la hora de dictaminar un castigo es su justificación pedagógica al interior de la razón evaluadora lo que le otorga la funcionalidad de enmendar y corregir, es decir, que el sujeto confesante se transforme con respecto a la falta cometida (y también con respecto a las que podría cometer) gracias al castigo sufrido. En este sentido, se instala así lo que Foucault (2014) llama "pacto punitivo" donde la confesión constituye un "compromiso punitivo" que da sentido a la sanción impuesta, al tiempo que legitima la soberanía de la institución que juzga y establece un "contrato de verdad" que permite a quien juzga/evalúa "saber con un saber indubitable" (p. 227).

Así, la confesión disipa incertidumbres, completa conocimientos fragmentarios y fortalece el sistema punitivo que es capaz, performativamente, de declarar culpable a un acusado y condenarlo. Pero también involucra una dramática en tanto "elemento que, en un escenario, pone de manifiesto el fundamento de legitimidad y sentido de lo que se desenvuelve en él" (Foucault, 2014, p. 228). Ahora bien, cuando algo escapa del procedimiento, cuando se dirige una pregunta que no es respondida o la respuesta es diferente a la esperada, se requiere sustituir o duplicar el dispositivo y ahí es donde entra en juego el examen que colmaría las lagunas, llenaría los espacios en blanco y produciría una subjetividad que mantuviera una relación significante con lo dicho. Esto último podría notarse cuando un evaluador le dice a un evaluado: "No te limites a decirme lo que has hecho sin decirme al mismo tiempo y por su intermedio quién eres" (Foucault, 2014, p. 233). Si se presta especial atención, es prácticamente la misma estructura de interpelación que subyace en la frase que analizábamos anteriormente ("Dime cómo evalúas y te diré qué tipo de profesional y de persona eres"), solo que en esta no hay una promesa de devolución, sino que está todo incluido en la misma solicitud (aunque, ciertamente, en la otra frase también lo está, solo que el evaluador es el único que lo sabe al contar con las clasificaciones de antemano).

$Y$ en caso de tener que dar cuenta de una falta o error, se podría escuchar también: "Dime quién eres, para que yo pueda tomar una decisión evaluativa que tendrá que estar a la altura de la falta que has cometido, pero también del individuo que eres". Esta podría ser una reversión evaluativa con el agregado de la falta en la que a fin de cuentas se establece una relación identitaria entre sujeto y error inscrita en la razón evaluadora: "Dime qué falta has cometido (y quién eres) y te diré qué decisión evaluativa te corresponde". Lo que está en juego es la relación problemática de un acto y su inteligibilidad, la relación de un acto con un sujeto, que no es simplemente asunto de causalidad más o menos libre, sino también de significación inscrita en determinada "hermenéutica del sujeto", como la llama Foucault (2014):

En la práctica de la espiritualidad cristiana, lo recordarán, la hermenéutica del sujeto consistía en esencia en una exposición de los secretos de la conciencia -de los arcana conscientiae- mediante el procedimiento del examen permanente de uno mismo y la verbalización exhaustiva dirigida a otro. Por medio de una serie de trabajos en que, desde luego, Freud y el psicoanálisis ocupan un lugar central, la hermenéutica del sujeto se abrió a finales del siglo XIX a un método de desciframiento muy alejado de la práctica del examen permanente y la verbalización exhaustiva (...). Se abrió una hermenéutica del sujeto, lastrada o cargada, que tenía por instrumento y por método principios de desciframiento tanto más cercanos a los principios de análisis de un texto. Esa hermenéutica del sujeto en forma de desciframiento de un texto debe permitir arraigar los comportamientos de un sujeto en un conjunto significativo. (p. 242). 


\section{Preguntas más acá y más allá del confesionario.}

Y así, hasta el "conjunto significativo" intenta ser corroborado cuando un evaluador pregunta a sus alumnos y alumnas: "¿Qué es lo más significativo que te ha pasado cuando te han evaluado en el sistema educativo?" -énfasis original- (Santos Guerra, 2017, p. 58), y confirma una tendencia habitual al tono negativo, al componente doloroso y amargo que una gran mayoría de relatos carga en relación a la evaluación. La expresión de "tatuajes en el alma", utilizada por el autor para titular la sección en la que comenta los efectos de su pregunta, es bastante descriptiva para un cierto arte del trauma inscripto en ese "conjunto significativo" que es la subjetividad, pero del que ni siquiera quedan dibujos agradables para ver(se) o mostrar a otros. Marcas que reactualizan los efectos inquisitoriales y su afán de pruebas: atemorizar, encasillar, causar miedo, hacer padecer injusticias, dolor, rabia, incluso humillaciones públicas que algunos pretenden que se las agradezcan en público (o en privado) tiempo después. O la introyección de descalificaciones que son mucho más que "dificultades para obtener éxito", así como el repertorio de somatizaciones a causa del estrés, la ansiedad, la competitividad y la exigencia de Ser "algo valioso" en una escala de calificaciones. Pero al evaluador pareciera "dolerle" que no se expresen experiencias "positivas" y que los relatos estén teñidos de sufrimiento, angustia e injusticia. ¿Cómo es posible que esa razón que intenta emparentarse con el corazón multiplique tantos testimonios donde se catalogan las más diversas formas de la arbitrariedad, la comparación, la represalia o el engaño?

$\mathrm{Si}$, al fin y al cabo, se puede reprobar, exigir, "no abogar por la blandura", "dar a cada uno lo que se merece", con el corazón. ¿Se referirá esto a marcar un pulso constante en la evaluación, como esos exámenes donde se decía que te tomaban "hasta el pulso"? Después de todo, "La misma experiencia a unos les hace aprender y a otros los embrutece. A unos los estimula y a otros los adocena" (Santos Guerra, 2017, p. 56), así como un aplazo (una reprobación) a unos los "estimula" y a otros los hunde, a unos los desafía y a otros los amedrenta. En este tipo de planteos evaluadores, siempre subyace una postura individualista donde llegan a encontrarse frases que resuenan mucho en el sentido común neoliberal, e incluso se emparentan con algunas frases de claro cuño ego-lógico como "solo es pobre el que quiere" y, en esa línea evaluadora, "solo aprende el que quiere" (Santos Guerra, 2017, pp. 75-77) y solo es "inteligente" quien es capaz de "ser feliz" y de "ser buena persona" (no es una ironía, puede encontrarse en la página 93 del mismo texto). Esa concepción del aprendizaje, y del mundo, se acompaña de concebir la justicia en términos de calificaciones, la educación en términos de exigencia y el tan mentado "rigor" (que nunca se desprende de su lado punitivo), la enseñanza como ensañamiento. De aquí que no sorprenda que al mismo tiempo que tanta gente padece (y siente) injusticias en este marco, tan poca se anime a reclamar. Si total el pánico le entra a otro, la caída libre es de otro, el amasijo ininteligible se le arma a otro, el examen se lo recogen a otro (cuando ni siquiera comenzó), el entendimiento lo pierde otro, la pluma se le cae a otro y no nos damos cuenta de que, en ese marco, cualquiera puede estar siendo ese otro.

¿Será que en todo evaluador palpita un fascista y ese es el sentido latente de la fórmula "evaluar con el corazón"? Tal vez sea una consecuencia de esa adopción apasionada del mecanismo y la técnica, "bajo la advocación de una energía falsificada" que "no puede hacer otra cosa, por falta de tiempo, que confundir el orden con la justicia", lo cual "Supone que la política es el arte de obedecer, se nutre de las emociones del récord brutal y en general de las manifestaciones más dramáticas del progreso mecánico" (Roca, 2008, p. 15). Solo cuando no hay escuela (o scholè), no hay tiempo libre, no se puede hacer otra cosa, se impone el orden de la obediencia a las cifras y al progreso como un drama constante de la respiración. En otras palabras, es precisamente lo que dice Deodoro Roca (2008) en un artículo de 1930: 
La vida moderna con su tráfago incesante, con sus incitaciones mecánicas, nos arrastra en su onda vertiginosa sobre el filo de las horas, sin dejarnos percibir ni gozar el sentido profundo del suceder, de "nuestro" suceder. Esa "falta de tiempo" de que todos se quejan, donde sucederían nuestras mejores hazañas (...) esa zona irreal en donde se proyecta la zona sombra "fugitiva" de lo que "quisimos" ser o de lo que "pudimos" ser, es el paraíso perdido de nuestro tiempo. La vida nos arrastra así, implacable (p. 88).

El filo de una temporalidad que rebana vidas, ajetrea los cuerpos hasta la extenuación, excita un fulgor vacuo que despoja de sensibilidad toda percepción de lo que (nos) pasa y siempre hace faltar tiempo para las mejores hazañas, para ser de otro modo que Ser o estar meramente estar. Lo implacable que nos arrastra no parece vida, sino un entrecruzamiento de tráfico, ondas satelitales y ruidos que, en la ardua velocidad que Roca (2008) en 1930 ya percibía, nos arrebata hasta la intimidad y nos instala en abismos indignos donde se siente que "nadie piensa, nadie lee, nadie sueña, nadie ama, nadie vive" (p. 88). Horas con pulso de kilowatt, de megabyte, de pixel, de algoritmos sin ningún ritmo, sin ninguna melodía, sin ninguna preocupación que coloree el paisaje serrano donde respira el alma que vive la sinuosidad del tiempo. Frente a las horas desteñidas de la época, como a Deodoro, nos estremece leve y dulce el aire del tiempo de la infancia que, con menos trajín en sus horas, despierta mayor conciencia de los instantes y se vive con un florecimiento interior abierto al sentido profundo y enigmático del suceder.

¿Será que habrá que hacer como esa "muchedumbre de almas incógnitas, desconocidas, que andan bajo vulgar apariencia por los caminos de la vida, sin el mezquino dolor de los que bregan por la notoriedad" (Roca, 2008, p. 12)? Como sugería Deodoro Roca en una revista de su Centro de Estudiantes en 1917, se trataría de tornarse invisibles a la mirada de quienes aprueban o denigran y no dejarse seducir por el sensualismo de la admiración y del aplauso, incluso aborrecerlo porque ahí está la trampa de la vanidad y del egoísmo que corrompe la sensibilidad. La razón evaluadora tienta con la nota, la notoriedad, ese retoño de la pura codicia que envenena el alma y sumerge el mundo en tinieblas que no permiten vernos ni entendernos, ni sentir cuando alguien sufre, haciendo del dolor un mal ajeno que no nos toca (por esa suerte siempre mezquina). Por eso, mientras haya una lágrima que enjugar, una iniquidad que reparar, una enseñanza que promover, habrá que luchar abnegadamente y con ardor. Y quien no tenga la convicción de haber hecho lo imposible en días de prueba, se entrega sin más a ese magisterio de cabeza helada y de mano atenta a una balanza menuda que solo quiere pesar lo brilloso, pero inerte.

\section{Evocación final: la denegación (y la última risa) en la confesión.}

En el año 2015 invitamos a Judith Butler a un seminario de grado que dictamos junto a un colega amigo en la Facultad de Filosofía y Letras de la Universidad de Buenos Aires. En ese marco, ofreció una conferencia sobre la confesión que versó sobre las formas de poder impuestas (por una autoridad externa, como la pedagógica, capaz de excluir y vigilar) que solo funcionan si el sujeto se ata a esos términos de poder y se forma a través de ellos. Desde ahí se trazó una interrogación sobre qué implica aflojar esas ataduras en tanto forma de desajustar o desconectarse de esos términos y en tanto forma de tornarse menos inteligible para la autoridad que los impone. Lo cual supone que la escena de direccionamiento, que entraña la confesión, instala un régimen de verdad que trabaja cuando quien es juzgado se constituye como identidad y comienza a ser reconocido desde lo que ella implica en su lógica. Esto establece condiciones identitarias en la formación del sujeto que solo pueden ser asumidas a través del repudio de la heterogeneidad: ser visto, ser escuchado, implica entrar en campos visibles y audibles que ya están estructurados por lo que puede ser visto y lo que puede ser escuchado. Así, al interiorizar esas estructuras, al afirmar la identidad conferida, se adquiere inteligibilidad para un régimen 
de verdad capaz de hacer convivir en el sujeto al subordinado y al subordinante de modo tal que alguien puede condenarse a sí mismo. No obstante, Butler da a entender que en el sujeto confesante hay un exceso semántico y semiótico que no puede estar contenido por los requerimientos formales impuestos sobre el acto de habla. A partir de este exceso, puede la confesión producir un descarrilamiento en relación a lo que las autoridades pedagógicas (y punitivas) esperan. Esta sería la denegación que resguarda el no saber o lo incognoscible al tiempo que impide a la ley totalizar al sujeto, al tiempo que hace fracasar la lógica de la identidad y designa la esfera de otro modo de deseo. Así se forma un sujeto más consciente de la ley y menos conocido por ella, que no ha absorbido el campo de poder dentro de la estructura de su propia reflexividad y ha excedido las demandas de la autoridad. Aquí se ubica la última risa en esta escena dramática.

\section{Referencias bibliográficas}

Esposito, R. (2011). El dispositivo de la persona. Buenos Aires: Amorrortu.

Foucault, M. (2014). Obrar mal, decir la verdad: la función de la confesión en la justicia. Curso de Lovaina, 1981. Buenos Aires: Siglo XXI.

Foucault, M. (2019). Historia de la sexualidad 4: Ias confesiones de la carne. Buenos Aires: Siglo XXI.

Giuliano, F. (2019). Entonces, ¿qué es un dispositivo? De la matriz colonial de poder a los dispositivos (pedagógicos) contemporáneos. Voces de la Educación, 4(8), 28-68. Disponible en URL: https://dialnet.unirioja.es/servlet/articulo?codigo=7017237

Nietzsche, F. (2013). Crepúsculo de los ídolos o Cómo se filosofa con el martilllo. Madrid: Alianza.

Roca, D. (2008). Obra reunida II: estética y crítica. Córdoba: Universidad Nacional de Córdoba.

Santos Guerra, M. Á. (2017). Evaluar con el corazón. De los ríos de las teorías al mar de la práctica. Rosario: Homo Sapiens. 